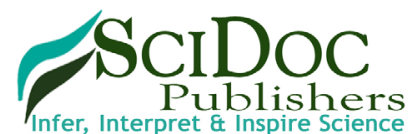

\section{Unilateral Nevoid Hyperkeratosis of the Nipple and Areola Treated Successfully With Carbon Dioxide Laser}

Case Report

Elloudi $\mathrm{S}^{1 *}$, Lahlou $\mathrm{A}^{1}$, Salim $\mathrm{G}^{1}$, Baybay $\mathrm{H}^{1}$, Rimani $\mathrm{M}^{2}$, Mernissi $\mathrm{FZ}^{1}$

${ }^{1}$ Department of Dermatology and Venereology, University Hospital Hassan II Fez, Morocco.

${ }^{2}$ Centre pathology Hassane, Rabat, Morocco.

\title{
Abstract
}

Nevoid hyperkeratosis of the nipple and areola (NHNA), is a rare benign condition characterized by papular warty excrescences on the nipple, the areola or both. We report a female patient with this rare condition appeared in postpartum and treated successfully by carbon dioxide laser.

Keywords: Nevoid Hyperkeratosis; Nipple; Areola; Postpartum; Carbon Dioxide Laser.

\section{Introduction}

Nevoid hyperkeratosis of the nipple and areola (NHNA), first described by Tauber [1] in 1923, is a rare benign condition with fewer than 70 cases reported in the literature. Nevoid hyperkeratosis presents as asymptomatic and hyperpigmented filiform or papular warty excrescences on the nipple, the areola or both. NHNA is commonly bilateral, and appear in women in their second or third decade, at puberty or during pregnancy [2], suggesting the role of hormone in its pathogenesis [1].

We report a female patient with this rare condition appeared in postpartum and treated Successfully by carbon dioxide laser.

\section{Case Report}

A 30-year-old woman presented with a 10 year history (just after her first child's birth) of hyperkeratotic and hyperpigmented lesions over her left nipple. She denied associated pain, pruritus, and discharge. The woman had not problems breast-feeding her child. There was no personal or family history of any dermatologic diseases. The evolution was marked for 1 year by the appearance of same lesions on the left areola, concomitant with taking oral contraception.

\begin{abstract}
Physical examination revealed brown irregular verrucous papules and plaques confined on the areola extending to nipple of the left breast (Figure 1). On palpation, the involved skin was not indurated, it was nontender and not adherent to the underlying structures. Breast examination was normal. The right nipple was normal. There was no other cutaneous lesions. There was no discharge from the nipple and no significant lymphadenopathy. Other systems were clinically normal. Dermoscopy's examination has not shown signs in favor of Bowen's disease, squamous cell carcinoma or warts (Figure 2).
\end{abstract}

Histopathologic examination showed hyperkeratosis, papillomatosis, acanthosis, and marked filiform interconnecting elongation of the rete ridges with hyperpigmentation, and keratin-filled spaces and ostia. The dermis revealed the perivascular infiltration of mononuclear inflammatory cells. There was a dense lymphocytic infiltrate in the dermis (Figure 3).

Treatment was performed with carbon dioxide laser. There was a total disappearance of the cutaneous lesions, including those from the nipple and areola (Figure 4). The patient was satisfied with the cosmetic outcome of the therapy. Hormonal contraception has been substituted with another method.

\footnotetext{
*Corresponding Author:

Sara Elloudi,

Department of Dermatology and Venereology, University Hospital Hassan II Fez, BP 1835, Atlass, Morocco.

E-mail: saraelloudi@gmail.com
}

Received: November 15, 2016

Accepted: December 01, 2016

Published: December 05, 2016

Citation: Elloudi S, Lahlou A, Salim G, Baybay H, Rimani M, et al., (2016) Unilateral Nevoid Hyperkeratosis of the Nipple and Areola Treated Successfully With Carbon Dioxide Laser. Int J Clin Dermatol Res, S1:001, 1-4. doi: http://dx.doi.org/10.19070/2332-2977-SI01001

Copyright: Elloudi $\mathbf{S}^{\circ}$ 2016. This is an open-access article distributed under the terms of the Creative Commons Attribution License, which permits unrestricted use, distribution and reproduction in any medium, provided the original author and source are credited. 
Figure 1. Papular Warty Excrescences on the Nipple, The Areola.

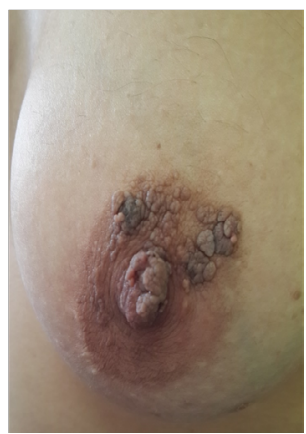

Figures 2. Dermoscopic Appearance: Filiform Excrescences without Signs in Favor Bowen's Disease, Squamous Cell Carcinoma or Warts.

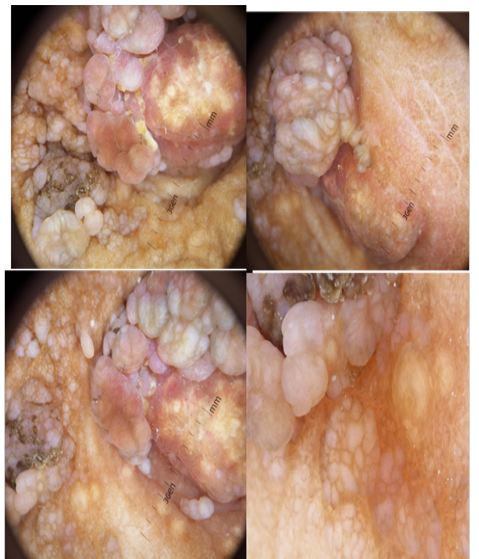

Figure 3. Coloration HES G x 50: Hyperacanthose + Papillomatose Irrégulière De L'épiderme + Hyperkératose.

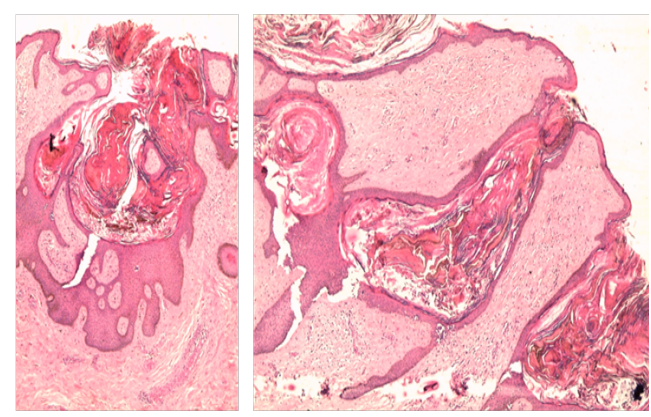

Figure 4. Total Disappearance of the Cutaneous Lesions with Carbon Dioxide Laser.

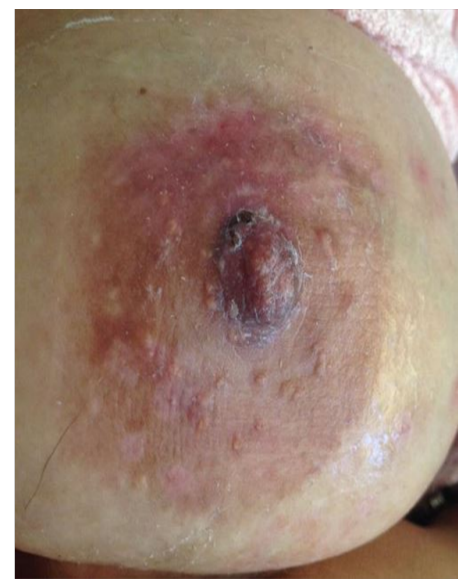




\section{Discussion}

NHNA was first described by Tauber in 1923 [1]. Then, LevyFrankel classified hyperkeratosis of the nipples and areolae into three categories [3]. Type 1 is an extension of epidermal nevus, this usually occurs unilaterally in both sexes. Type 2 is associated with other dermatoses, such as acanthosis nigricans, atopic dermatitis, ichthyosis, Darier disease, or lymphoma. This type may be bilateral. The third type is idiopathic hyperkeratosis of the nipple and areola, this rare condition is also called naevoid hyperkeratosis and it appears predominantly in women in the second or third decade of life, and is usually bilateral $[4,5]$. But there are reports of unilateral lesions also $[6,7]$ like our patient.

The etiology of NHNA is still unknown. A change in estrogen milieu has been proposed as a possible mechanism [8]. Among the cases reported in the littterature, one has been reported as having appeared during pregnancy [9]. In another case, nevoid hyperkeratosis appeared in a 60-year-old man with associated gynecomastia, who developed these lesions after orchidectomy and diethylstilbestrol therapy for cancer of the prostate [10].

In our case, lesions appeared in postpartum and are extended after taking oral contraception, which supports once again hormonal theory in this condition. Typically, NHNA presents as hyperkeratotic, hyperpigmented plaques of the nipple and/or areola $[4,5]$. Desquamation [11] or Yellowish discoloration $[12,13]$ or of the areas may also be present. Occasionally, the lesions appear verrucous [14]. Generally, erythema, induration and discharge do not occur. The lesions may involve the nipple, the areola, or both. Kubota et al., [15] reviewed 45 cases of nevoid hyperkeratosis in which $17 \%$ of cases involved the nipple, $25 \%$ of cases involved the areola, and the remaining $58 \%$ of cases involved both the nipple and the areola.

NHNA is a diagnosis of exclusion [16]. NHNA needs to be differentiated from epidermal naevus, acanthosis nigricans, chronic eczema, atopic eczema, seborrhoic keratosis, Darier's disease, Paget's disease, basal cell carcinoma, dermatophytosis, mycosis fungoide and Bowen's disease $[14,17,18]$. These diagnoses were ruled out after dermoscopic examination in our patient.

These disorders can be distinguished from NHNA by correlating clinical and histological features. There are several histological features which characterize NHNA $[6,17,18]$.

The epidermis shows orthokeratotic hyperkeratosis and occasional keratotic plugging. There is marked elongation of the epidermal rete ridges with variable papillomatosis.

The basal layer of the epidermis is hyperpigmented without associated melanocytic proliferation. There may be a mild perivascular lymphocytic infiltrate within the dermis.

The main cause for concern in patients of NHNA is cosmetic appearance of nipple and areola. and rarely may interfere with breast-feeding $[7,11]$.

Various treatment modalities have been reported including topical corticosteroids, topical calcitriol [19], topical and oral retinoids [20], topical keratolytics, surgical techniques including cryother- apy excision [14, 15, 21, 22], radiofrequency ablation [23], and laser [24]. A case of NHNA was successfully treated with carbon dioxide laser [21] and no recurrence was seen. The current case too was effectively treated with ablative carbon dioxide laser with a good cosmetic outcome. No recurrence has occurred so far, 8 months post-treatment.

\section{Conclusion}

NHNA is a rare benign condition. It is a diagnosis of exclusion. Dermoscopy helps to eliminate some differential diagnosis. Biopsy is essential to establish the diagnosis. Various therapies have been used for treatment of HNA with varying extent of efficacy. Our patient will be treated with the ablative carbon dioxide laser, which provides good cosmetic results with a minimum of scarring.

\section{References}

[1]. Baykal C, Buyukbabani N, Kavak A, Alper M (2002) Nevoid hyperkeratosis of the nipple and areola: A distinct entity. J Am Acad Dermatol. 46(3): 414418. [PMID: 11862178]

[2]. Higgins HW, Jenkins J, Horn TD, Kroumpouzos G (203) Pregnancy-associated hyperkeratosis of the nipple : a report of 25 cases. JAMA Dermatol. 149(6): 722-726. [PMID: 23616176]

[3]. Lee HW, Suh HS, Choi JC, Lee MW , Choi JH, et al., (2005) Hyperkeratosis of the nipple and areola as a sign of malignant acanthosis nigricans. Clin Exper Dermatol. 30(6) : 707-726. [PMID: 16197404]

[4]. Revert A, Montesinos E, Jorda E (1993) Nevoid hyperkeratosis of the areola. Int J Dermatol. 32(10): 745-746. [ PMID: 8225720]

[5]. Alpsoy E, Yilmaz E, Akyol A (1997) Hyperkeratosis of nipple: Report of two cases. J Dermatol. 24: 43-45. [PMID: 9046740]

[6]. D'Souza M, Gharami R, Ratnakar C, Garg BR (1996) Unilateral nevoid hyperkeratosis of the nipple and areola. Int J Dermatol. 35(8): 602-603. [PMID: 8854169]

[7]. Shastry V, Betkerur J, Kushalappa PA (2006) Unilateral nevoid hyperkeratosis of the nipple: A report of two cases. Indian J Dermatol Venereol Leprol. 72(4): 303-305. [PMID: 16880580]

[8]. Chikhalkar SB, Misri R, Kharkar V (2006) Nevoid hyperkeratosis of nipple: Nevoid or hormonal? Indian J Dermatol Venereol Leprol. 72(4): 384-386. [PMID: 17050940 ]

[9]. Rodallec J, Moral P, Guilaine C, Civatte J (1978) Recurring unilateral hyperkeratosis of the areola of the nipples in a pregnant women. Ann Dermatol Venereol. 105(5): 527-528. [PMID: 707944]

[10]. Schwartz RA (1978) Hyperkeratosis of the nipple and areola. Arch Dermatol. 114(12): 1844-1845. [PMID: 736593]

[11]. Perez-Izquierdo J, Vilata J, Sanchez J, Gargallo E, Millan F, et al., (1990) Retinoic acid treatment of nipple hyperkeratosis. Arch Dermatol. 126: 687Đ688. [PMID: 2334197]

[12]. Ollague W (1979) Hyperkeratosis of the nipple. Arch Dermatol. 115: 111. [PMID: 760652]

[13]. Xifra M, Lagodin C, Wright D, Abbruzzese M, Woscoff A (1999) Nevoid keratosis of the nipple. J Am Acad Dermatol. 41(2): 325Đ326. [PMID: 10426921]

[14]. Mitxelena J, Raton J, Bilbao I, Diaz-Perez J (1999) Nevoid hyperkeratosis of the areola in men: response to cryotherapy. Dermatol. 199(1): 73-74. [PMID : 10449968]

[15]. Kubota Y, Koga T, Nakayama J, Kiryu H (2000) Naevoid hyperkeratosis of the nipple and areola in a man. Br J Dermatol. 142(2): 370-393. [PMID: 10730786]

[16]. English J, Coots N (1996) A man with nevoid hyperkeratosis of the areola. Cutis. 57(5): 354-356. [PMID: 8726719]

[17]. Başak Yalçın, Güneş, Ekici O, Tabanlioqlu-Onan D (2014) Mycosis fungoides mimicking nevoid hyperkeratosis of the nipple and areola in an adolescent. Turk J Pediatrics. 56(5): 565-567. [PMID : 26022599]

[18]. Ilana S Rosman, Hepper DM, Lind AC, Anadkat MJ (2012) Nevoid hyperkeratosis of the areola misinterpreted as mycosis fungoides. J Cutan Pathol. 39(5): 545-548. [PMID: 22515226 ]

[19]. Guevara-Gutierrez E, Tarango-Martınez VM, Sandoval-Tress C, Hernandez-Torres M (2008) Unilateral nevoid hyperkeratosis of the nipple and areola treated with topical calcitriol. Actas Dermosifiliogr. 99(6): 500-501. 
[PMID: 18558069]

[20]. Toros P, Onder M, Gurer MA (1990) Bilateral nipple hyperkeratosis treated successfully with topical isotretinoin. Australas J Dermatol. 40(4): 220-222. [PMID: 10570562]

[21]. Fenniche S, Badri T (2010) Nevoid hyperkeratosis of the nipple and areola. N Engl J Med. 362: 1618. [PMID: 20427810]

[22]. Swan MC, Gwilym SE, Hollowood K, Venning V, Cassell O (2004) Treatment of nevoid hyperkeratosis of the nipple and areola by shave excision. Ann Plast Surg. 53(5): 510-512. [PMID: 15502472]

[23]. Ozyazgan I, Kontas O, Ferahbas A (2005) Treatment of nevoid hyperkeratosis of the nipple and areola using a radiofrequency surgical unit. Dermatol Surg. 31(6): 703-705. [PMID: 15996425]

[24]. Busse A, PeschenM, Schop fE, Vanscheidt W (1999) Treatment of hyperkeratosis areolae mammae naeviformis with the carbon dioxide laser. J Am Acad Dermatol. 41(2): 274. [PMID: 10426904]

\section{Special Issue on}

"Cosmetic Dermatology"

\section{Edited by:}

Cantisani Carmen, Consultant Dermatologist, Sapienza University of Rome, Italy.

E-mail: carmencantisanister@gmail.com 